\title{
Is Vaccination an Option for Treating Rabies?
}

\section{Nicholas Johnson*}

Animal Health and Veterinary Laboratories Agency, Woodham Lane, Addlestone, Surrey, KT15 3NB, UK

Vaccination against rabies is unique in that it is used post-exposure to prevent disease. This is due to the extended incubation period between exposure and the first signs of disease, often measured in months but occasionally measured in years [1]. It is still not clear what the virus does during this period, however, it offers the opportunity to intervene with treatment. Currently there is no antiviral treatment despite extensive investigation [2], but there is sufficient time to inoculate with a number of licensed inactivated virus vaccines that induce an effective immune response that stops the virus progressing to infection of the central nervous system. All well and good, but what happens if no action is taken post exposure to a bite from a rabid animal. This is where the rabies virus shows its ruthless side. There are no certain statistics for how many people progress from exposure through a bite, to the development of disease, an overwhelming encephalomyelitis, but for those that do there is little hope of survival. One attempt to address that has been the development of therapeutic coma as a form of treatment for those presenting with the signs of rabies. This approach has been pioneered by Dr Rodney Willoughy following its successful use to treat a teenager who developed rabies following a bat bite [3]. The treatment remains controversial as there are no models for evaluating the method, which has been evolving for the past seven years as more experience is gained from its use. However, in spite of the small number of successes, the treatment has not been successful in the majority of cases that it has been applied [4]. There are no clear indicators of what dictates a successful outcome although survivors tend to be younger and have been infected with a bat variant rather than the more commonly encountered dog variant, they also develop high titres of neutralizing antibodies early in the disease and this is found both in the blood and cerebrospinal fluid. Treatment is also dependent on a rabies diagnosis being made early to trigger action and the patient requires constant monitoring during the period of sedation. Where a post-mortem has been conducted on patients that die following therapy, high levels of rabies virus are present throughout the brain [4] suggesting that antiviral treatment either by an antiviral or an immune-mediated response is needed to augment therapeutic coma.

One approach that could offer some support has been through the development of vaccine candidates based on the reverse genetics approach. It is now almost 20 years since Conzelmann and Schnell reported the first recovery of rabies virus from a cloned genome [5]. Since this time the approach has been developed by a number of laboratories in Europe and the United States in pursuit of improved understanding of the biology of the virus and the development of attenuated viruses for use as vaccine candidates [6,7]. One popular approach has been to introduce mammalian innate immune response genes into the rabies virus genome, usually between the glycoprotein gene and the L polymerase gene [8-10]. The effect of these introductions when tested in a murine model attenuates the virus through overstimulation of the innate immune response, preventing infection of the central nervous system. This is manifested as high levels of circulating anti-rabies virus antibodies and increased recruitment of dendritic cells into lymph nodes following inoculation with recombinant virus with no indication of virulence. One group of researchers has taken this a step further and used a modified rabies virus containing the gene for Granulocyte-Macrophage Colony Stimulating Factor (GM-CSF) as a form of a vaccine therapy [11]. By first infecting mice with a virulent strain and then re-infecting the mice with the attenuated strain, they have shown prevention of death from a lethal infection. This effect was observed in mice inoculated with modified virus up to 5 days post infection with a virulent rabies virus strain by the intracerebral route. Elevated levels of neutralizing antibodies were observed in inoculated mice and increased infiltration of inflammatory cells into the brain.

However, mice are not men, and there is a long way to go before this could be considered as a possible therapeutic approach. Nonetheless, there are currently no treatments for rabies other than therapeutic coma. Pre- and post-exposure vaccination is highly effective at preventing disease although this is not enough. While there are still rabid dogs and bats in the world, there will always victims of this disease who slip through the public health net either through lack of resources or ignorance. Any treatment that can be devised with direct or indirect antiviral activity would offer hope to those that develop rabies.

\section{References}

1. Johnson N, Fooks AR, McColl K (2008) Human rabies case with long incubation, Australia. Emerg Infect Dis 14: 1950-1951.

2. Dacheux L, Delmas O, Bourhy H (2011) Human rabies encephalitis prevention and treatment: progress since Pasteur's discovery. Infect Disord Drug Targets 11: $251-299$.

3. Willoughby RE Jr, Tieves KS, Hoffman GM, Ghanayem NS, Amlie-Lefond CM, et al. (2005) Survival after treatment of rabies with induction of coma. N Engl J Med 352: 2508-2514.

4. Hunter M, Johnson N, Hedderwick S, McCaughey C, Lowry K, et al. (2010) Immunovirological correlates in human rabies treated with therapeutic coma. Med Virol 82: 1255-1265

5. Conzelmann KK, Schnell M (1994) Rescue of synthetic genome RNA analogs of rabie virus by plasmid encoded proteins. J Virol 68: 713-719.

6. Faber M, Dietzschold B, Li J (2009) Immunogenicity and safety of recombinant rabies viruses used for oral vaccination of stray dogs and wildlife. Zoonoses Public Health 56: 262-269.

7. Faber M, Pulmanausahakul R, Hodawadekar SS, Spitsin S, McGettigan JP, et al. (2009) Overexpression of the rabies virus glycoprotein results in enhancement of apoptosis and antiviral immune response. J Virol 76: 3374 3381

8. Faul EJ, Wanjalla CN, McGettigan JP, Schnell MJ (2008) Interferon-beta expressed by a rabies virus-based HIV-1 vaccine vector serves as a molecular adjuvant and decreases pathogenicity. Virology 382: 226-238.

*Corresponding author: Nicholas Johnson, Animal Health and Veterinary Laboratories Agency, Woodham Lane, Addlestone, Surrey, KT15 3NB, UK, E-mail: Nick.Johnson@ahvla.gsi.gov.uk

Received June 29, 2012; Accepted June 29, 2012; Published July 03, 2012

Citation: Johnson N (2012) Is Vaccination an Option for Treating Rabies? J Vaccines Vaccin 3:e104. doi:10.4172/2157-7560.1000e104

Copyright: (c) 2012 Johnson N . This is an open-access article distributed unde the terms of the Creative Commons Attribution License, which permits unrestricted use, distribution, and reproduction in any medium, provided the original author and source are credited. 
9. Zhao L, Toriumi H, Wang H, Kuang Y, Guo X, et al. (2010) Expression of MIP1 alpha (CCL3) by a recombinant rabies virus enhances its immunogenicity by inducing innate immunity and recruiting dendritic cells and B cells. J Virol 84: 9642-9648.

10. Wen Y, Wang H, Wu H, Yang F, Tripp RA, et al. (2011) Rabies virus expressing dendritic cell-activating molecules enhances the innate and adaptive immune response to vaccination. J Virol 85: 1634-1644.

11. Wang H, Zhang G, Wen Y, Yang S, Xia X, et al. (2011) Intracerebral administration of recombinant rabies virus expressing GM-CSF prevents the development of rabies after infection with street virus. PLoS One 6: e25414. 